\title{
Transient Repression of Erythromycin Formation in Streptomyces erythraeus
}

\author{
By LAURA ESCALANTE, HECTOR LOPEZ, ROSA DEL CARMEN \\ MATEOS, FERNANDO LARA AND SERGIO SANCHEZ* \\ Departamento de Biotecnología del Instituto de Investigaciones Biomédicas, Universidad \\ Nacional Autónoma de México, Apdo Postal 70228, México, D.F. 04510 Mexico
}

(Received 2 November 1981)

\begin{abstract}
The effect of D-glucose on growth and erythromycin production by Streptomyces erythraeus was investigated. D-Glucose stimulated growth and caused a strong but temporary suppression of antibiotic formation. Maximum specific suppression of erythromycin formation occurred at a carbohydrate concentration of $20 \mathrm{mg} \mathrm{m}^{-1}$. A non-metabolizable analogue of glucose, 2-deoxy-D-glucose, also suppressed antibiotic formation. Since glucose caused a decrease in erythromycin formation only when added before the stage of antibiotic production, we conclude that this sugar exerted a transient repressive effect on erythromycin biosynthesis.
\end{abstract}

\section{INTRODUCTION}

The formation of many antibiotics and other secondary metabolites is suppressed by rapidly used carbon sources (Martin \& Demain, 1980). Among such carbon sources, glucose seems to be one of the most effective in exerting a negative influence on antibiotic biosynthesis (Hu \& Demain, 1979).

The antibiotic erythromycin is a secondary metabolite formed by strains of Streptomyces erythraeus at the end of the trophophase (Smith et al., 1962). Since it is a broad-spectrum antibiotic and has low toxicity for humans, erythromycin is of great medical and economic importance (Oleinik, 1975). In spite of the practical interest of erythromycin, very little has been published involving the regulatory aspects of its biosynthesis (Corcoran, 1975; Raczynska-Bojanowska et al., 1970; Spizek et al., 1965).

In the present work, the effect of D-glucose on growth and erythromycin production by $S$. erythraeus was examined in a medium which eliminated changes due to $\mathrm{pH}$ variation. The experimental evidence obtained here indicated that this carbohydrate exerted a transient repression on erythromycin formation.

\section{METHODS}

Organisms and cultivation. Streptomyces erythraeus BM 21-115 wild-type strain, was obtained from the UNAM-Biomédicas Culture Collection. Sarcina lutea NRRL B-1018, was kindly supplied by the ARS Culture Collection, U.S. Department of Agriculture, Peoria, Ill., U.S.A.

All cultures were grown in a complex medium $(\mathrm{CM})$ containing $0.4 \mathrm{~g}$ yeast extract and $0.3 \mathrm{~g}$ malt extract per $100 \mathrm{ml}$ of $0.1 \mathrm{M}-3-\left(N\right.$-morpholino)propanesulphonic acid buffer (Sigma), pH 7.0. Approximately $10^{8} S$. erythraeus spores (from a $5 \mathrm{~d}$ old culture grown on a solid CM medium slant) were inoculated into CM medium $(10 \mathrm{ml})$ contained in a $50 \mathrm{ml}$ Erlenmeyer flask and were incubated at $29{ }^{\circ} \mathrm{C}$ for $8 \mathrm{~h}$ on a rotary shaker $(160 \mathrm{rev}$. $\left.\mathrm{min}^{-1}\right)$. For antibiotic production, a sample $(1 \mathrm{ml})$ of the above culture was inoculated into $\mathrm{CM}$ medium $(50 \mathrm{ml})$ contained in a $250 \mathrm{ml}$ Erlenmeyer flask and was incubated at $29^{\circ} \mathrm{C}$ for $72 \mathrm{~h}$. D-Glucose was sterilized separately 
and added to $\mathrm{CM}$ medium at desired concentrations just prior to inoculation. Under these conditions $S$. erythraeus BM 21-115 produced mainly erythromycin A, shown by TLC (Martin \& Goldstein, 1970). Experiments were carried out in triplicate. Erythromycin production, $\mathrm{pH}$ and growth of $S$. erythraeus were monitored throughout the fermentation.

Assay of erythromycin. At specified intervals, the production of antibiotic was determined by a disc-agar plate technique (Aharonowitz \& Demain, 1978), using Sarcina lutea as the assay organism. After incubation $\left(37^{\circ} \mathrm{C}\right.$, $15 \mathrm{~h}$ ), zones of inhibition were measured and the amount of erythromycin was estimated using erythromycin $\mathbf{A}$ (Fermic Laboratories S. A., México 13, D. F.) as standard.

Growth determination. Samples of mycelia were harvested, washed with 2 vol. distilled water and placed in $2 \mathrm{ml}$ of $0.3 \mathrm{M}$-trichloroacetic acid. After centrifugation, the pellet was resuspended in $1 \mathrm{ml}$ of $0.4 \mathrm{M}-\mathrm{NaOH}$ and its protein concentration was determined by the Lowry method using bovine serum albumin as standard.

\section{RESULTS}

Streptomyces erythraeus BM 21-115 produced erythromycin when it was grown in CM medium at $29^{\circ} \mathrm{C}$. Under these conditions, production started at $36 \mathrm{~h}$ of incubation and continued linearly for approximately $50 \mathrm{~h}$. When the amount of erythromycin produced was plotted as a function of growth (Fig. 1), a close relationship between these parameters was obtained. On the other hand, when D-glucose was added to the medium, this relationship was modified by an increase in the extent of growth and a delay in antibiotic production.

To gain more information about the glucose effect, several concentrations of the carbohydrate were tested for growth and erythromycin formation (Fig. 2). D-Glucose stimulated both parameters but suppressed the specific antibiotic synthesis without significant changes in the $\mathrm{pH}$ of the medium. The maximum effect was reached at a concentration of $20 \mathrm{mg} \mathrm{ml}^{-1}$. Further increase in the concentration (up to $100 \mathrm{mg} \mathrm{ml}^{-1}$ ) did not significantly modify the level of suppression (not shown).

To find out whether or not glucose itself was responsible for this action, the effect on growth and erythromycin production by a non-metabolizable glucose analogue, 2deoxy-D-glucose (Tyler et al., 1967) was determined. As shown in Table 1 the analogue significantly decreased antibiotic production but had no effect on growth. In addition, higher concentrations (up to $20 \mathrm{mg} \mathrm{ml}^{-1}$ ) of the analogue almost totally inhibited the production of erythromycin.

Suppression was observed when glucose was added either at the beginning of the fermentation or during the exponential growth phase, but before the stage of antibiotic synthesis (Fig. 3). Once the production of erythromycin had started, addition of glucose did not modify the linear relationship between erythromycin production and growth.

\section{DISCUSSION}

The use of D-glucose as major carbon and energy source resulted in changes in maximum growth and in production of erythromycin. This carbohydrate brought about a strong but temporary suppression of antibiotic formation. During the period of this suppression, the growth rate was increased so that the effect of glucose was not to arrest the overall synthesis of protein, but to prevent antibiotic formation specifically. Similar effects on the suppression of other secondary metabolites by glucose have been reported previously (Gallo \& Katz, 1972; Redshaw et al., 1976; Satoh et al., 1976).

Maximum specific suppression of antibiotic formation occurred with $20 \mathrm{mg}$ D-glucose $\mathrm{ml}^{-1}$. The sugar, rather than a product derived from its catabolism, seemed to be responsible for this action since a non-metabolizable glucose analogue also suppressed erythromycin formation.

That glucose suppressed the specific erythromycin formation only when added before the antibiotic production phase indicated a repressive rather than an inhibitory or inactivating effect. The kinetics of this action are similar to those reported for the transient repression of 


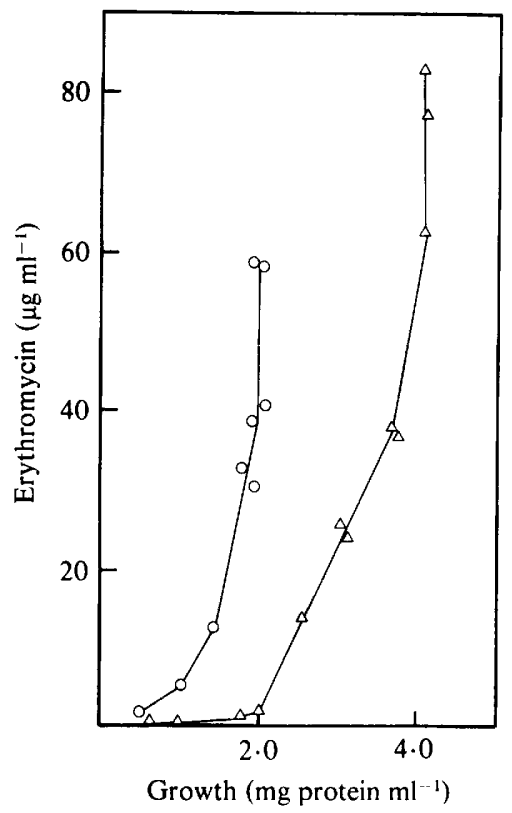

Fig. 1. Effect of D-glucose on erythromycin formation. Cultures were grown in CM medium with $(\triangle)$ or without (O) D-glucose (10 $\left.\mathrm{mg} \mathrm{ml}^{-1}\right)$.

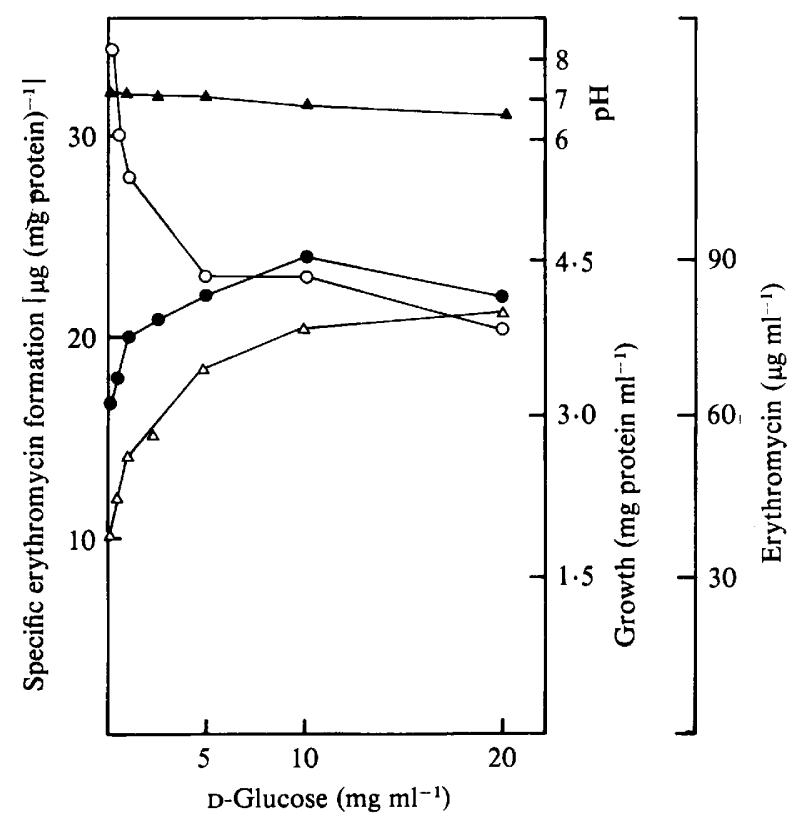

Fig. 2. Effect of different D-glucose concentrations on the maximum growth $(\Delta)$, erythromycin formation (O), final $\mathrm{pH}$ of the medium $(\boldsymbol{\Delta})$ and specific erythromycin formation $(\mathrm{O})$.

$\beta$-galactosidase elicited by glucose in Escherichia coli (Tyler et al., 1967). As pointed out by these authors, a transient repressive effect is characterized by a strong but temporary suppression in the formation of a given metabolite. 
Table 1. Effect of 2-deoxy-D-glucose on maximum growth and erythromycin formation by

\section{S. erythraeus}

2-Deoxy-D-glucose was filter-sterilized through a Millipore membrane type HAWP 02500 before addition to $\mathrm{CM}$ medium. Growth and erythromycin formation were determined after incubation at $29^{\circ} \mathrm{C}$ for $72 \mathrm{~h}$.

2-Deoxy-D-glucose
(mg ml
(-1)
None
10
20

\begin{tabular}{|c|}
\hline $\begin{array}{c}\text { Growth } \\
\left(\mathrm{mg} \text { protein } \mathrm{ml}^{-1}\right)\end{array}$ \\
\hline $\begin{array}{l}1.8 \\
2.0 \\
1.8\end{array}$ \\
\hline
\end{tabular}

$\overbrace{\left(\mu \mathrm{g} \mathrm{ml}^{-1}\right)}^{\text {Erythromycin formation }}$

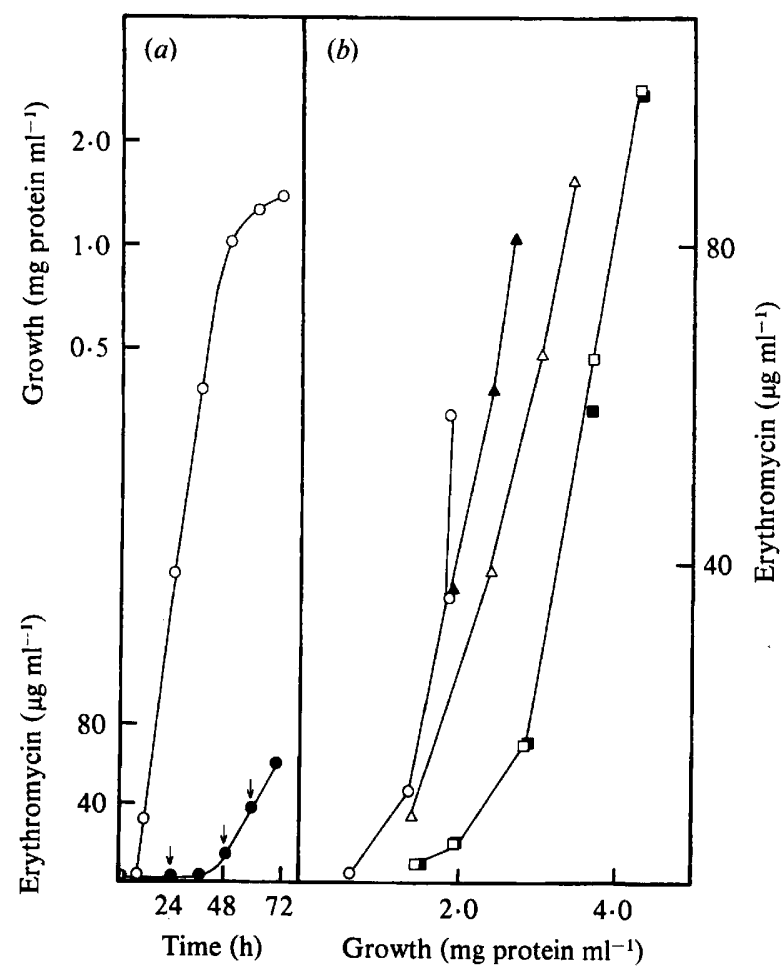

Fig. 3. Effect of the time of D-glucose addition on growth and erythromycin production by $S$. erythraeus. (a) Control without glucose showing the erythromycin produced $(O)$ and the growth $(O)$ at the time of glucose addition (arrows). (b) Erythromycin formation obtained with glucose $\left(10 \mathrm{mg} \mathrm{ml}^{-1}\right)$ being added at the beginning of the experiment $(\square)$ and $24 \mathrm{~h}(\square), 48 \mathrm{~h}(\Delta)$ and $60 \mathrm{~h}(\Delta)$ later. O, Control without sugar.

On the basis of these previous observations, the experimental evidence obtained in the present investigation indicated that glucose exerted a transient repression on erythromycin formation.

We are indebted to A. Farres, A. Gonzalez-Sarabia, J. E. Herz and V. Yakoleff-Greenhouse for critical reading and helpful suggestions. 


\section{REFERENCES}

Aharonowitz, Y. \& Demain, A. L. (1978). Carbon catabolite regulation of cephalosporin production in Streptomyces clavuligerus. Antimicrobial Agents and Chemotherapy 14, 159-164.

CorCoran, J. W. (1975). Antibiotic biosynthesis. Methods in Enzymology 43, 487-498.

Gallo, M. \& KaTZ, E. (1972). Regulation of secondary metabolite biosynthesis: catabolite repression of phenoxazinone synthase and actinomycin formation by glucose. Journal of Bacteriology 109, 659-667.

Hu, W. S. \& DemaIn, A. L. (1979). Regulation of antibiotic biosynthesis by utilizable carbon sources. Process Biochemistry 14, 2-6.

Martín, J. F. \& Demain, A. L. (1980). Control of antibiotic biosynthesis. Microbiological Reviews 44, 230-251.

Martin, J. R. \& Goldstein, A. W. (1970). Final steps in erythromycin biosynthesis. In Progress in Antimicrobial Agents and Anticancer Chemotherapy, vol. 2, pp. 1112-1116. Tokyo: University of Tokyo Press.

OleINICK, N. L. (1975). The erythromycins. In Antibiotics, vol. 3, pp. 396-419. Edited by J. W. Corcoran \& F. E. Hahn. New York: SpringerVerlag.

RACZYNSKa-BojanOWSKa, K., RuczaJ, Z.,
OSTROWSKA-KRYSIAK, B., ROSZKOWSKI, J., GAWOROWSKA-MICHALIK, J. \& SAWNORKorszYNSKA, D. (1970). Precursors and control in erythromycin biosynthesis. Acta microbiologica polonica 2, 103-110.

Redshaw, P. A., McCann, P. A., Sankaran, L. \& Pogell, B. M. (1976). Control of differentiation in streptomycetes: involvement of extrachromosomal deoxyribonucleic acid and glucose repression in aerial mycelia development. Journal of Bacteriology 125, 698-705.

Satoh, A., Ogawa, H. \& Satomura, Y. (1976). Regulation of $\mathrm{N}$-acetylkanamycin amidohydrolase in the idiophase in kanamycin fermentation. Agricultural and Biological Chemistry 40, 191-196.

Smith, R. L., Bungay, H. R. \& Pittenger, R. C. (1962). Growth-biosynthesis relationships in erythromycin fermentation. Applied Microbiology 10, 293-296.

Spizek, J., Chick, M. \& Corcoran, J. W. (1965). Biogenetic relationship of the erythromycins and the lactone of erythromycin B. Antimicrobial Agents and Chemotherapy 5, 138-143.

Tyler, B., LoOmIs, W. F. \& MAgasanik, B. (1967). Transient repression of the lac operon. Journal of Bacteriology 94, 2001-2011. 